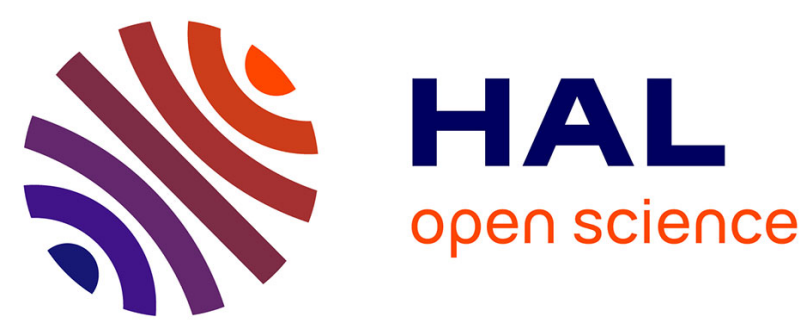

\title{
Microwave bonding of poly(methylmethacrylate) microfluidic devices using a conductive polymer
}

R.J. Holmes, C. Mcdonagh, J.A.D. Mclaughlin, S. Mohr, N.J. Goddard, P.R. Fielden

\section{- To cite this version:}

R.J. Holmes, C. Mcdonagh, J.A.D. Mclaughlin, S. Mohr, N.J. Goddard, et al.. Microwave bonding of poly(methylmethacrylate) microfluidic devices using a conductive polymer. Journal of Physics and Chemistry of Solids, 2011, 72 (6), pp.626. 10.1016/j.jpcs.2011.02.005 hal-00753048

\author{
HAL Id: hal-00753048 \\ https://hal.science/hal-00753048
}

Submitted on 17 Nov 2012

HAL is a multi-disciplinary open access archive for the deposit and dissemination of scientific research documents, whether they are published or not. The documents may come from teaching and research institutions in France or abroad, or from public or private research centers.
L'archive ouverte pluridisciplinaire HAL, est destinée au dépôt et à la diffusion de documents scientifiques de niveau recherche, publiés ou non, émanant des établissements d'enseignement et de recherche français ou étrangers, des laboratoires publics ou privés. 


\section{Author's Accepted Manuscript}

Microwave bonding of poly(methylmethacrylate) microfluidic devices using a conductive polymer

R.J. Holmes, C. McDonagh, J.A.D. McLaughlin, S. Mohr, N.J. Goddard, P.R. Fielden

PII:

S0022-3697(11)00029-1

DOI: doi:10.1016/j.jpcs.2011.02.005

Reference: PCS 6405

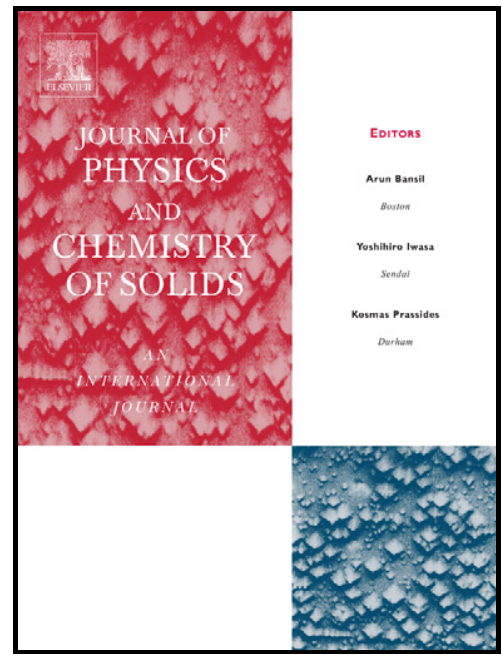

www.elsevier.com/locate/jpcs

To appear in: $\quad$ Journal of Physics and Chemistry of Solids

Received date: $\quad 2$ July 2010

Revised date: $\quad$ 19 January 2011

Accepted date: $\quad 11$ February 2011

Cite this article as: R.J. Holmes, C. McDonagh, J.A.D. McLaughlin, S. Mohr, N.J. Goddard and P.R. Fielden, Microwave bonding of poly(methylmethacrylate) microfluidic devices using a conductive polymer, Journal of Physics and Chemistry of Solids, doi:10.1016/j.jpcs.2011.02.005

This is a PDF file of an unedited manuscript that has been accepted for publication. As a service to our customers we are providing this early version of the manuscript. The manuscript will undergo copyediting, typesetting, and review of the resulting galley proof before it is published in its final citable form. Please note that during the production process errors may be discovered which could affect the content, and all legal disclaimers that apply to the journal pertain. 


\title{
Microwave bonding of poly(methylmethacrylate) microfluidic devices using a conductive polymer
}

\author{
RJ. Holmes ${ }^{a 1}, C_{\text {McDonagh }}{ }^{a}$, JAD McLaughlin ${ }^{a}$, S Mohr $^{b}$, NJ. Goddard ${ }^{b}$ and PR. Fielden ${ }^{b}$

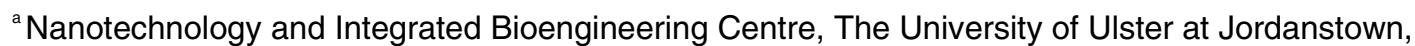 \\ Newtownabbey, Co. Antrim, BT37 0QB, Northern Ireland.UK \\ ${ }^{\mathrm{b}}$ The School of Chemical Engineering and Analytical Science, The Manchester Interdisciplinary Bioscience \\ Centre, The University of Manchester, 131 Princess Street, Manchester, M1 7DF.UK
}

\begin{abstract}
Component binding within microfluidic devices is a problem that has long been seeking a solution. In this investigation, the use of microwave radiation to seal PMMA components has been investigated using polyaniline as an absorber capable of inducting interfacial bonding. Straight microchannels were machined into PMMA using a Datron CAT3DM6 CNC machine with widths and depths across a range of 100 to 1000 microns. Prototype fluidic devices were prepared with channel patterns utilizing varying feature sizes, bends and flow profiling to demonstrate the application of the technique to real microfluidic devices. Experimental data illustrated the successful bonding of channels in the range stated previously and bonding (tensile) strength was assessed via pull tests on bonded PMMA using an Engstrom Zwick 100 tensile testing system (Engstrom Ltd, US). Coherent, defect free seals were attained with breakage tests requiring in excess of $1 \mathrm{kN}$ of force.
\end{abstract}

\section{Keywords}

Microfluidics, PMMA, Microwave, Bonding, CNC Machining.

\section{Submitted to}

Journal of Physics and Chemistry of Solids

\footnotetext{
${ }^{1}$ To whom correspondence should be addressed. T: 02890368433 ; E: rj.holmes@ulster.ac.uk
} 


\section{Introduction}

Microfluidic devices have attracted a great deal of attention in recent years with applications spanning the agri-food, biomedical and industrial sectors and encompassing both diagnostics and microreactor platforms $[1,2,3]$. The complexity of the devices can vary greatly and range from intricate nano architectures and microelectromechanical (MEMS) devices to more modest adhoc constructions - vital for rapid prototyping and proof of concept studies [4]. Irrespective of the methods employed, the sealing of the microfluidic path is a non-trivial task, and whilst many methods have been investigated to achieve the latter, few have found mainstream implementation. Since the ability to bond similar materials and thus provide a uniform wettable surface at all boundaries is essential in a large number of microfluidic applications, a low-cost technique that is able to facilitate the development of such a device would clearly be a significant asset to the toolbox of the microfluidics scientist. The present communication has sought to investigate the applicability of one such approach and assess its viability for bonding polymethylmethacrylate (PMMA) such that a closed channel architecture can be easily produced which is readily accessible without the need for expensive instrumentation.

There are a multitude of methods to generate microfluidic features in a range of materials, from silicon and glass to plastics and silicone elastomers - each has distinct advantages and disadvantages depending on the final application [5]. However, the methods available to bond these devices to a substrate, thereby sealing the system are limited to the use of adhesives, solvents and heat / pressure. One of the biggest problems with any sealing technique is the blockage of fine microchannels during the bonding procedures [6]. The work presented in this article is intended to overcome a significant problem when dealing with PMMA, namely that it is difficult to bond to itself unless heated above the glass transition point $(\mathrm{Tg})$ of $105^{\circ} \mathrm{C}[7,8]$, and subjected to considerable pressure. For a significant number of microfludics systems, a uniform surface chemistry in all dimensions is essential as changes in the wettable nature of the materials affects flow profiles [9].

Numerous methods have been proposed to overcome this issue and have included the use of ultrasonics [10, 11], solvent / adhesive bonding [12-14], thermal bonding [15,16] and electrostatics [17]. There are few methods that offer a low cost rapid and simple technique to the co-bonding of PMMA microdevices. Microwave radiation has been previously proposed [15 - 19] as a potential solution, however due to the transparent 
nature of PMMA (99.5\%) to radiation in the $2.45 \mathrm{GHz}$ region, it is essential to introduce an absorbing layer that can induce the two surfaces to bond. Various systems have been proposed and these have been extensively reviewed [18], with Polyaniline extensively studied as a conductive polymer for use in bonding plastics, due in no small part to its high dielectric constant $(\sim 100,000)$ and the fact that it is commercially available and easily prepared into nano powder dispersions.

The central rationale for this work is that a thin layer of polyanline delivered simply through capillary action between the two surfaces would create a microlayer that would absorb the microwave radiation - increasing the interfacial temperature at end plate and thus induce bonding without unduly disrupting the microchannels that are etched into the core of the plates.

\section{Experimental Details}

Materials and General Methods: All reagents were of the highest grade available and used without further purification. Polymethylmethacrylate sheets (4mm thick, Goodfellows, UK) were cut into $75 \mathrm{~mm}$ square sections. Polyaniline was obtained from Sigma as the powder (MW >15,000, 3 - 100 $\mu \mathrm{m}$ particle size) and suspend in methanol as a $0.2 \% \mathrm{w} / \mathrm{w}$ solution. Micro-channel features were designed using a CAD package (TurboCAD Mac Pro, IMSI Software, UK) and converted into tooling paths using EdgeCAM (Planit Software, UK). The designs were machined in PMMA slabs $75 \mathrm{~mm}$ square and $4 \mathrm{~mm}$ thick using a Datron CAT3DM6 precision CNC machine (Datron Technology, UK). Precision tungsten carbide milling tools in the range of 50 - 1000 microns were purchased from Datron Technology.

Bonding Procedure: An all-plastic bonding frame system was constructed in-house, consisting of 4 sets of parallel PMMA beams, linked with PMMA screw threads and PMMA wing-nuts (RS Components, UK). This was used to apply localized pressure and was tightened to finger tight pressures only. An illustration of the bonding frame is shown in Figure 1. A high power domestic microwave (Panasonic NN-ST459W, 900W) was used for the bonding experiments. 
A $0.02 \% \mathrm{w} / \mathrm{v}$ polyaniline solution in methanol - a solvent which has minimal effect on PMMA (reagents from Sigma Aldrich, UK) was prepared and added between the machined components prior to clamping in the bonding frame. This concentration of polyaniline was chosen based on initial experiments aimed at determining the optimum concentration suitable for use. Once fitted in the frame, capillary action drove the polyaniline solution to all parts of the device, and volumes of solution were added via the fluid access holes as required. Excess solution was found to be advantageous to the bonding procedure.

The PMMA device, mounted in the bonding frame was placed in the microwave oven and exposed to microwave radiation at $2.45 \mathrm{GHz}$ and exposed in increments of 30 seconds until bonding was judged (using the change in refractive index at the bonging sites as an indicator). The full power (900W) setting was used throughout the experimental procedure, and lower power settings were not attempted in this study. The device was then removed from the oven, allowed to cool and tested with an amaranth solution $(0.05 \% \mathrm{w} / \mathrm{v})$ with photographs of the devices taken to illustrate the channel integrity. The capillaries were subsequently inspected by light microscopy to assess the transfer of the dye into microcrevices arising from the incomplete bonding of the plates.

\section{Results and Discussion}

Experiments were conducted using a range of channel widths and depths, as shown below to obtain a more accurate picture of the bonding characteristics for different microchannel structures. Each PMMA device comprised 10 channels, with two duplicates of each device prepared and tested with bonding successfully obtained for every channel combination and are summarized in Table 2. The results of the bonding process associated with two PMMA sheets and subsequent dye penetration is highlighted in figure 2.

\begin{tabular}{|c|c|c|c|c|c|}
\hline $\begin{array}{c}\text { Part } \\
\text { N.o }\end{array}$ & $\begin{array}{c}\text { Width } \\
(\mu \mathrm{m})\end{array}$ & $\begin{array}{c}\text { Depth } \\
(\mu \mathrm{m})\end{array}$ & $\begin{array}{c}\text { Part } \\
\text { N.o. }\end{array}$ & $\begin{array}{c}\text { Width } \\
(\mu \mathrm{m})\end{array}$ & $\begin{array}{c}\text { Depth } \\
(\mu \mathrm{m})\end{array}$ \\
\hline $1 \& 2$ & 1000 & 1000 & $3 \& 4$ & 800 & 1000 \\
\hline $1 \& 2$ & 1000 & 800 & $3 \& 4$ & 800 & 800 \\
\hline
\end{tabular}




\begin{tabular}{|c|c|c|c|c|c|}
\hline $1 \& 2$ & 1000 & 500 & $3 \& 4$ & 800 & 500 \\
\hline $1 \& 2$ & 1000 & 300 & $3 \& 4$ & 800 & 300 \\
\hline $1 \& 2$ & 1000 & 100 & $3 \& 4$ & 800 & 100 \\
\hline & & & & & \\
\hline $1 \& 2$ & 500 & 1000 & $3 \& 4$ & 300 & 1000 \\
\hline $1 \& 2$ & 500 & 800 & $3 \& 4$ & 300 & 800 \\
\hline $1 \& 2$ & 500 & 500 & $3 \& 4$ & 300 & 500 \\
\hline $1 \& 2$ & 500 & 300 & $3 \& 4$ & 300 & 300 \\
\hline $1 \& 2$ & 500 & 100 & $3 \& 4$ & 300 & 100 \\
\hline
\end{tabular}

Table 1: Table showing dimensions of machined microchannels in PMMA used for bonding experiments.

Additionally, planar PMMA devices without microchannel features were bonded and subjected to tensile testing using an Engstrom Zwick testing station (Engstrom, US). PMMA devices were clamped in the vice-claw and subjected to breaking loads in excess of $1.0 \mathrm{kN}$, with displacement distance (Mean: $0.85 \mathrm{~mm}$; RSD $=11.6 \% ; \mathrm{N}=6$ ) and breaking force recorded (Mean: $1.175 \mathrm{kN} ; \% \mathrm{RSD}=12.3 \% ; \mathrm{N}=6$ ). It should be noted that in all cases the un-bonded PMMA region broke before the bonded area.

A second series of microfluidic channel plates were prepared in PMMA demonstrating a range of channel dimensions, flow profiles and features. These were bonded using the same procedure as above, and photographs of the channels filled with polyaniline were obtained to illustrate the channel integrity. Figure 3 and figure 4 comprise of CAD illustrations of the microchannel structure and the corresponding photograph of the bonded device, illustrating the successful bonding of devices with 300-micron feature sizes (Figure 3) and 50-micron feature sizes (Figure 4)

The method produced a uniform bond, easily observed by the change in refractive index across the device indicating that localized melting had occurred across the entire device interface. This can be attributed to the fine nano-particulate suspension of the conductive polymer across the plates that serve as antennae for the microwave radiation. Whilst the entire device warms during the process, the energy delivered during the bonding process is insufficient to produce bulk melting $\left(\sim 160^{\circ} \mathrm{C}\right.$ for PMMA) but is sufficient to result in a localized melt zone at the interface that creates a tight, solvent impermeable bond. The duration of microwave exposure was arrived at through iterative optimization starting at a 30 second exposure with the 3 minutes established as providing a coherent seal. 
The micro-channel integrity was found to be maintained, with small feature sizes creating no problems in terms of fluidic movement - confirmed by optical microscopy and DekTak profiling of the channel before and after irradiation (not shown). It should be noted that the method described results in the presence of polyaniline particles within the channel as well as at the bonding interface. This could affect surface chemistries inside the device however given the localized heating at the particles and the low concentrations of polyaniline required to effect bonding, the magnitude of any effect should be minimized.

It is a rapid technique which is eminently suitable for prototyping but could equally find use in the mass-production of microfluidic devices manufactured from PMMA, using a plastic roller system rather than a discrete clamping mechanisms - thus giving rise to a truly low cost, disposable and yet intricate microfluidic device.

\section{Conclusions}

The use of PMMA is widespread and one of the most common materials for microfluidic prototyping. This work has demonstrated a low cost, rapid and easily implemented bonding system to achieve PMMA to PMMA bonding using a conventional microwave oven. The system was found to provide a coherent seal free from micro-crevice defects that can plague other systems with an absorber that does not unduly impact on the nature of the integral microfluidic channel.

\section{References}

1. Beebe, DJ., Mensing, GA., and Walker, GM., Ann. Rev. Biomed. Eng., 4, (2002) pp $261-266$.

2. Whitesides, GM., Nature, 442 (27), (2006), pp $368-373$.

3. Holmes, RJ., Summersgil, P., Ryan, T., Treves Brown, BJ., Mockbil, A., Grieve BD., and PR. Fielden, Journal of Food Science, 74(6), 2009, pp. N37 - N43. 
4. Li, SW., Xu, JH., Wang, YC., and Luo, GS., J. MicroMech and Microeng. 19, (2009), pp $1-6$.

5. Sun, Y., Satyanarayan, MVD., Nguyen, NT., Kwok, YC., Sensors and Actuators B, 130, (2008), pp $836-841$.

6. Spierings, GACM., J. Haisma, J., and van der Kruis, FJHM., Phillips J. Res, 49, (1995) pp 139 - 149.

7. Grab, B., Neyer, A., Jöhnck, M., Siepe, D., Eisenbeb, F., Weber, G., Hergenröder, R., Sensors and Acutuators B, 72, (2001) pp 249 - 258.

8. Li, SW., Xu, JH., Wang, YJ., Lu, YC., and Luo, GS., J. MicroMech and Microeng. 19, (2009), pp $1-6$.

9. Truckenmuller, R., Ahrens, R., Cheng, Y., Fischer, G., and Volker Saile, V., Sensors and Actuators A, 132, (2006) pp 385 - 392

10. Umbrecht, F., Müller, D., Gattiker, F., Boutry, CM., Neuenschwander, J., Sennhauser, U and Hierold, Ch., Sensors and Actuators A, 156 (1), (2009) pp 121128.

11. Tsao, CW., and DeVoe, DL., Microfluid. Nanofluid, 6, (2009), pp 1 - 16.

12. Sun, X., Peeni, BA., Yang, W., Becerril, HA., Woolley, AT., J. Chrom. A., 1162, (2007), pp. 162 - 166.

13. Yi, L., Xiaodong, W., and Fan, Y., J. Mat. Proc. Tech., 208, (2008) pp 63-69

14. Abgrall, P., Low, LN., and Nguyen NT., LabChip, 7, (2007) pp. 520 - 522.

15. Lui, J-S., Liu, C., Guo, JH., and Wang LD., J. Mat. Proc. Tech, 178, (2006) pp 278 282

16. Staicovici, S., Wu, CY., and Benatar A., J. Reinforced Plastics and Composites, 18 (1), (1999), pp. $35-43$.

17. Yussuf, AA., Sbarski, I., Hayes, JP., Solomon, M., and Tran, N., J. Micromech. Microeng., 15, (2005), pp. 1692 - 1699.

18. Lei, KF., Ahsan, S., Nasser Budraa, S., Li, WJ., and Mai, JD., Sensors and Actuators A, 114, (2004) pp. 340 - 346.

19. Folgueras, LdeC., Nohara, EL., Faez, R., and Rezende, MC., Mat. Research, 10 (1), (2007), pp. 95 - 99. 


\section{Figure Legends}

Figure 1 Illustration of the all-plastic bonding frame used for microwave bonding of PMMA.

Figure 2 Photograph of straight microchannels in PMMA filled with Amaranth to indicate sealed channels - channels widths 500 microns (LHS) \& 300 micron (RHS) - channel depths 1000, 800, 500, 300 and 100 microns.

Figure 3 Illustration of microchannel and photomicrograph of microchannel showing a $1.2 \mathrm{~mm}$ channel with 300 micron side inlets and a 200 micron central barrier structure.

Figure 4 Illustration of microchannel and photograph of microchannel showing a 500 micron channel, 300 micron side inlets and twin 50 micron barrier structures. 


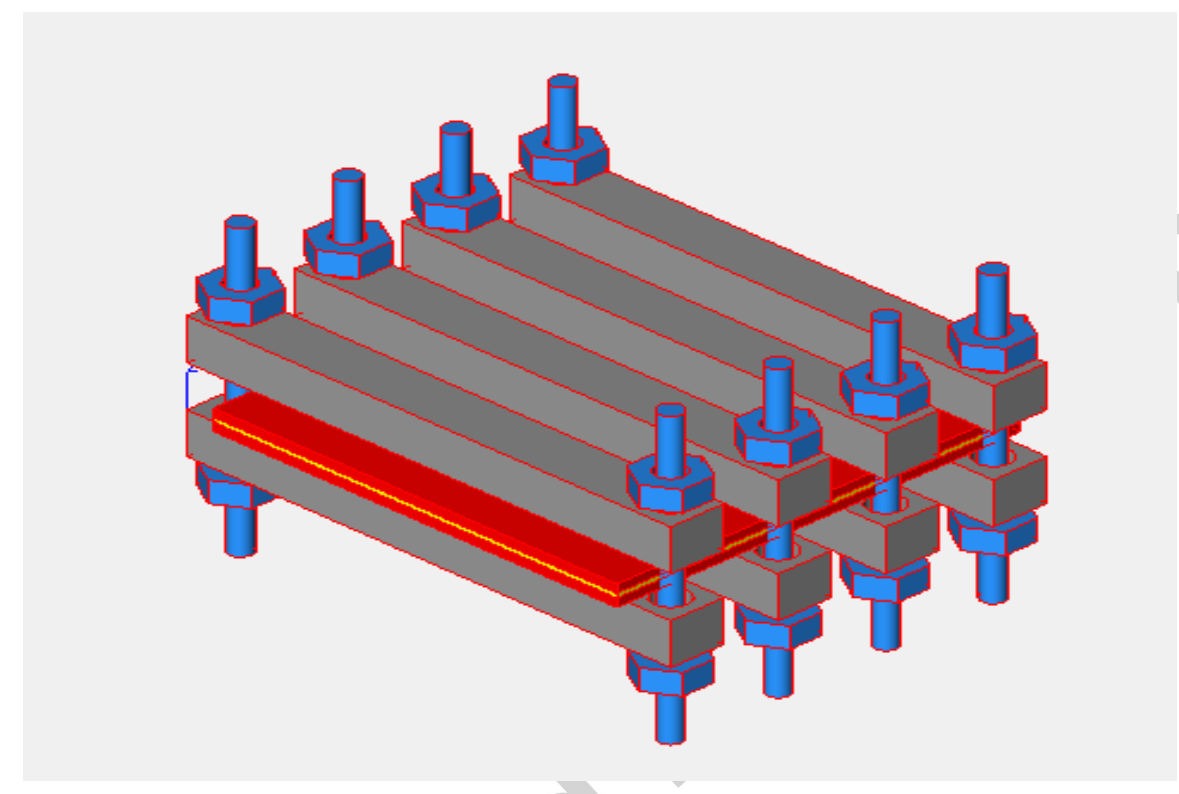

Figure 1: Illustration of the all-plastic bonding frame used for microwave bonding of PMMA. 


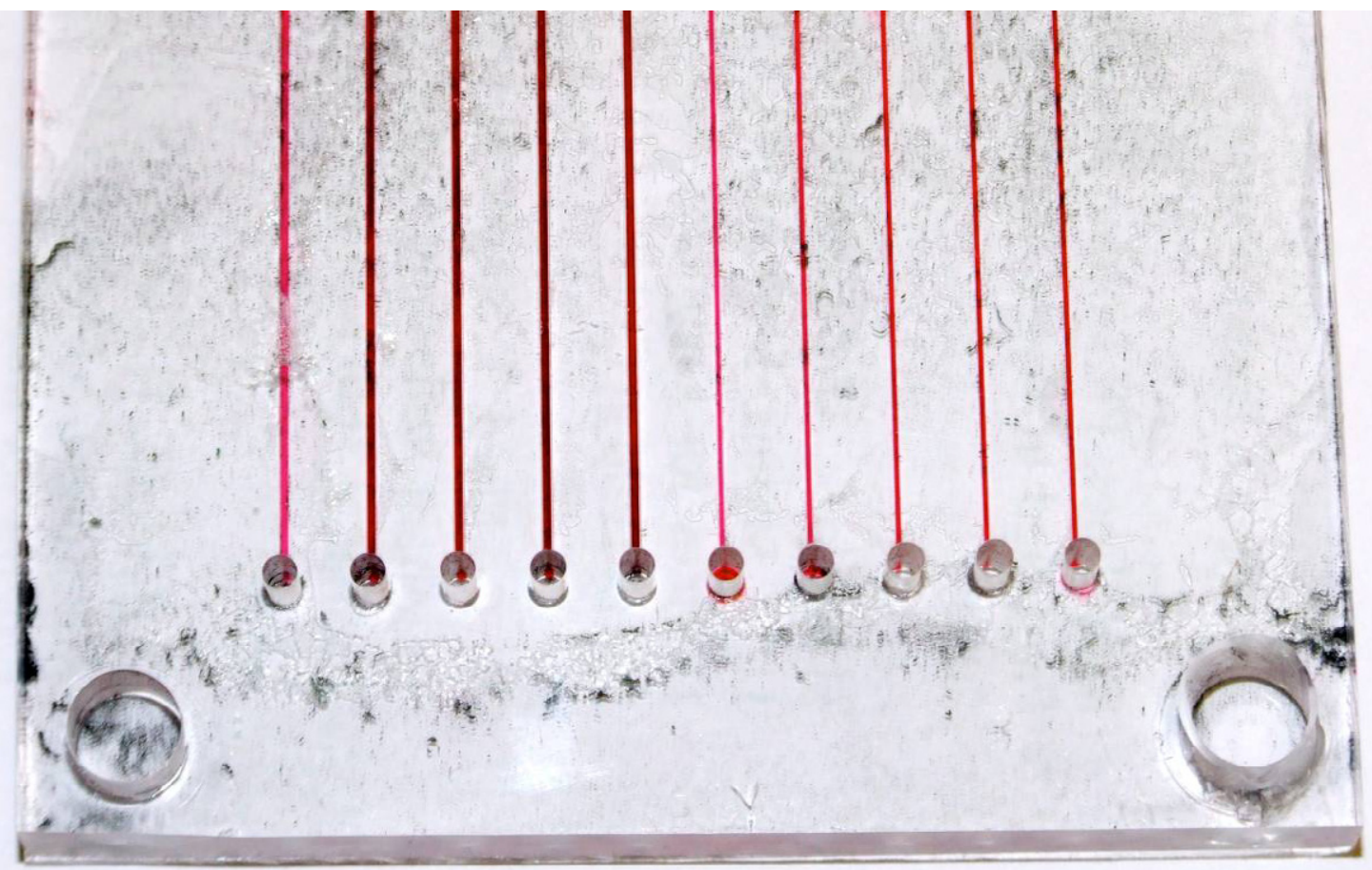

Figure 2: Photograph of straight microchannels in PMMA filled with Amaranth to indicate sealed channels - channels widths 500 microns (LHS) \& 300 micron (RHS) - channel depths $1000,800,500,300$ and 100 microns. 

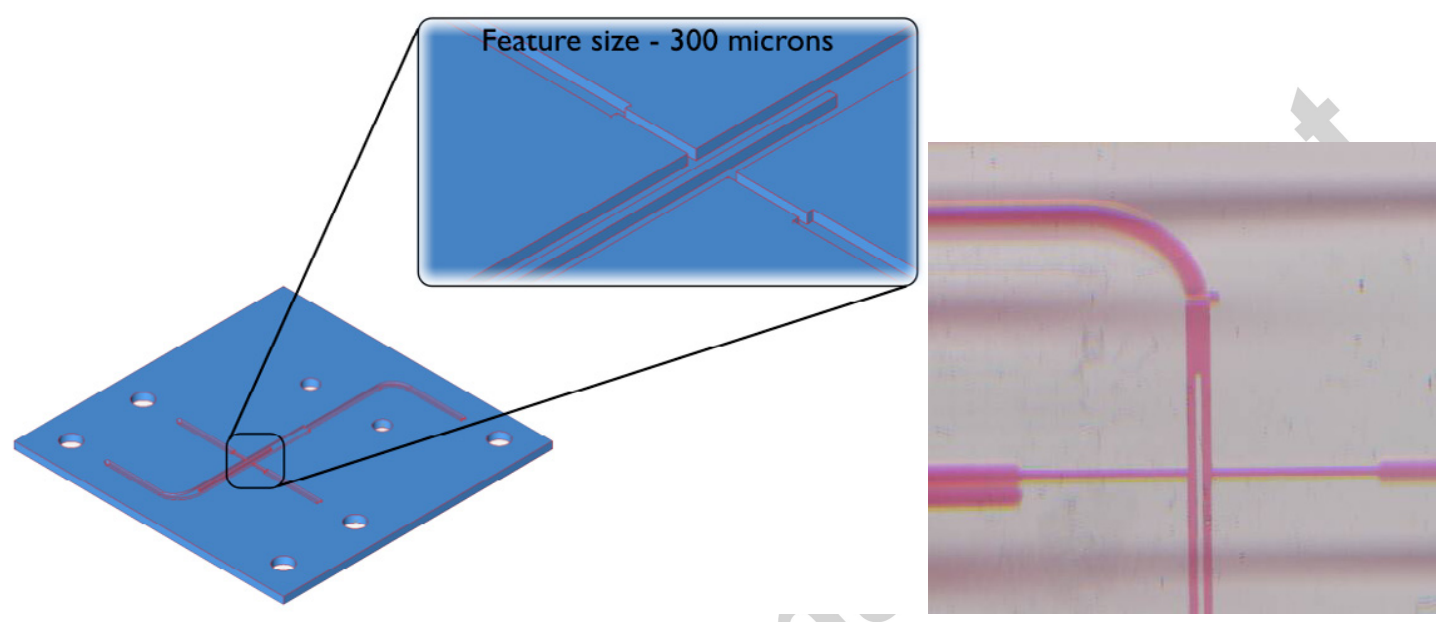

Figure 3: Illustration of microchannel and photomicrograph of microchannel showing a $1.2 \mathrm{~mm}$ channel with 300 micron side inlets and a 200 micron central barrier structure. 

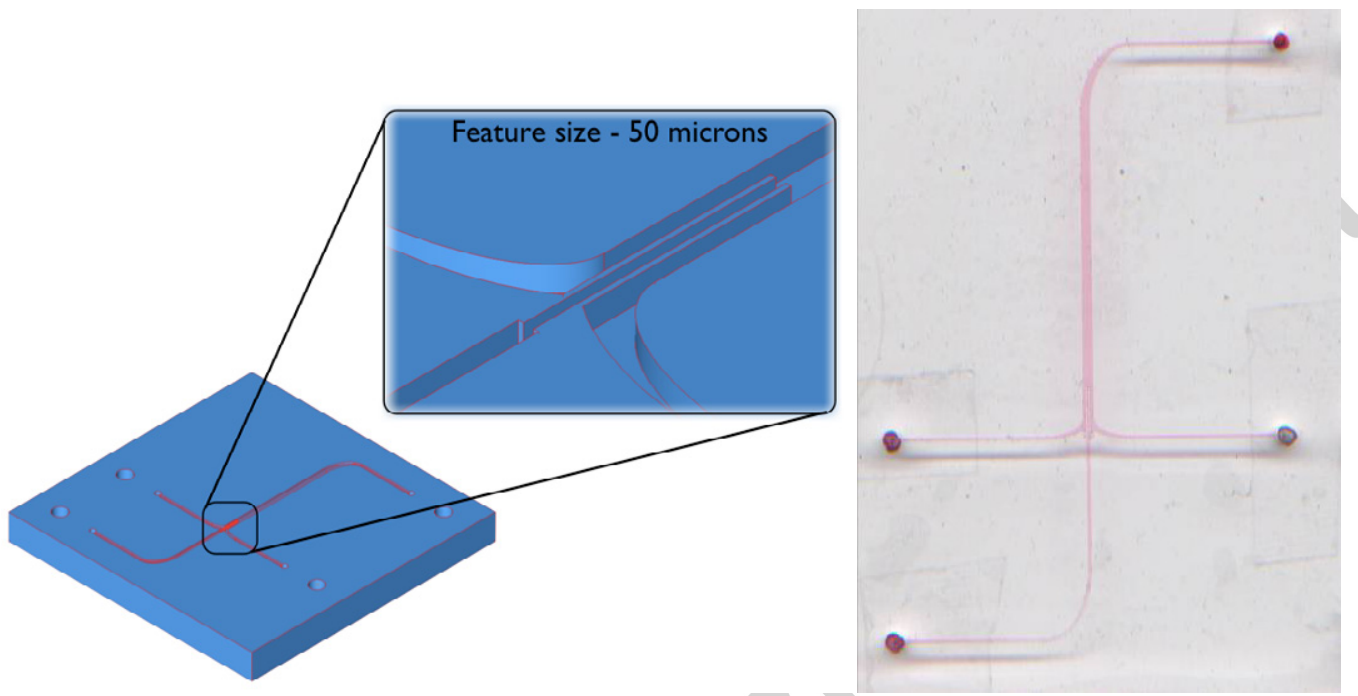

Figure 4: Illustration of microchannel and photograph of microchannel showing a $\mathbf{5 0 0}$ micron channel, $\mathbf{3 0 0}$ micron side inlets and twin $\mathbf{5 0}$ micron barrier structures. 
Ms. Ref. No.: PCS-D-10-00565

Title: Microwave bonding of poly(methylmethacrylate) microfluidic devices using a conductive polymer

Journal of Physics and Chemistry of Solids

\section{Research Highlights}

- Microwave bonding of polymer microfludics devices

- $\quad$ Rapid and low cost device fabrication

- $\quad$ Localized thermal bonding method. 